\title{
A 2-D numerical model of the mechanical behavior of the textile-reinforced concrete composite material: effect of textile reinforcement ratio
}

\author{
Tien ManhTran ${ }^{1,}$, Tu Ngoc Do ${ }^{1}$, Ha Thu Thi Dinh ${ }^{1}$, Hong Xuan Vu ${ }^{2}$, Emmanuel \\ Ferrier $^{2}$ \\ ${ }^{1}$ Faculty of Mining, Hanoi University of Mining and Geology, Vietnam \\ 2 Université de LYON, Université Claude Bernard LYON 1; Laboratoire des Matériaux Composites pour la \\ Construction LMC2, France
}

\section{ARTICLE INFO}

Article history:

Received 08 ${ }^{\text {th }}$ Feb. 2020

Revised $17^{\text {th }}$ May 2020

Accepted $30^{\text {th }}$ June 2020

\section{Keywords:}

Basalt textile,

Mechanical behavior,

Numerical modeling.

Reinforcement ratio,

Textile-reinforced concrete (TRC).

\section{ABSTRACT}

The textile-reinforced concrete composite material (TRC) consists of a mortar/concrete matrix and reinforced by multi-axial textiles (carbon fiber, glass fiber, basalt fiber, etc.). This material has been used widely and increasingly to reinforce and/or strengthen the structural elements of old civil engineering structures thanks to its advantages. This paper presents a numerical approach at the mesoscale for the mechanical behavior of TRC composite under tensile loading. A 2-D finite element model was constructed in ANSYS MECHANICAL software by using the codes. The experimental results on basalt TRC composite from the literature were used as input data in the numerical model. As numerical results, the basalt TRC provides a strain-hardening behavior with three phases, depending on the number of basalt textile layers. In comparison with the experimental results, it could be found an interesting agreement between both results. A parametric study shows the significant influence of the reinforcement ratio on the ultimate strength of the TRC composite. The successful finite element modeling of TRC specimens provides an economical and alternative solution to expensive experimental investigations.
${ }^{*}$ Corresponding author

E-mail: tranmanhtien@humg.edu.vn DOI: 10.46326/JMES.2020.61(3).04

\section{Introduction}

Over the past two decades, TRC (Textile Reinforced Concrete) composite materials have become increasingly and widely used for reinforcement or strengthening of old structures because of their advantages. The TRC composite 
consists of a mortar/concrete matrix reinforced by multi-axial textiles (carbon fiber, glass fiber, basalt fiber, etc.) (Butler and et al., 2010; Mechtcherine, 2013). The main purpose of this composition is to improve the mechanical properties of TRC material. Good tensile strength of reinforcement textiles could compensate for the traditional weakness of the cement matrix and the sensitivity of matrix to cracking.

In case of reinforcement or strengthening of existing construction structures (slab, beam, column, etc.), the structure is bent under the action of mechanical loading, and the TRC composite material works as a bar in traction. With a high tensile strength improved and attributed by the textile reinforcement, the TRC composite plays an important role in the stability of the structures as well as a protection against the reaction of the ambient environment.

In the literature, there are several experimental studies on the mechanical behavior of the TRC composite under the tensile or bending loading (Contamine, 2011; Mobasher and et al., 2006; Rambo and et al., 2015; 2016; 2017). Rambo and et al., 2015, performed direct tensile tests on the composite specimens of the basalt textile reinforced alumina cement concrete. Colombo and et al., 2011, carried out tensile tests on the TRC specimens based on the AR glass fiber reinforced Portland cement matrix. Most of these studies showed the strain-hardening behavior of TRC specimens, which can be divided generally into three distinct phases. The resistance and Young's modulus at different zones depend considerably on parameters such as the fiber type (carbon fiber, glass fiber or basalt fiber...), the properties of the fiber (resistance, Young's modulus), the reinforcement ratio (Hegger and et al., 2006; Rambo and et al., 2016), the cementitious matrix type (Mobasher and et al., 2006; Brameshuber, 2006), the pre-impregnation treatment of the interface between fiber and matrix by different products in nature (Hegger and Voss. 2008; Rambo and et al., 2015), etc. Therefore, to take into account the effect of these factors on the mechanical behavior of TRC composite, it is necessary to do a lot of direct traction tests for this characterization. It will be interesting to have another approach to this problem.
A numerical approach will allow reducing the number of tests for the characterization of the mechanical behavior of TRC composite. By using the finite element method, the TRC's behavior can be determined from numerical tests of mesoscale modeling. It means that from the constituent material properties, the overall behavior and ultimate strength of the TRC composite can be predicted. In literature, there were several numerical modeling at multi-scale concerning the tensile behavior of TRC composite under mechanical loading (Truong, 2016; Djamai and et al., 2017). These models gave interesting results which link to the tress-strain relationship, the ultimate strength as well as failure modes of specimens. They also presented a good agreement with the experimental result.

To the best of the authors' knowledge, no results are available concerning the 2-D mesoscale modeling by the finite element method for the TRC composite. There are also not yet numerical results regarding the effect of the reinforcement ratio on its mechanical behavior. This paper presents numerical results concerning the mechanical behavior of basalt TRC composite by using the ANSYS MECHANICAL 15.0 software. A numerical model was constructed from two types of elements in the 2-D model: PLAN183 element for the basalt textile and the cement matrix, and the INTER203 element for the fiber/matrix interface. The experimental results in ref (Rambo et al., 2015; Rambo et al., 2016; Rambo et al., 2017) were used as the input data. The results obtained from the 2-D numerical model were used to compare with that of the experimental studies. The influence of the reinforcement ratio on the stress-strain relationship and the ultimate strength of the TRC composite was found and analyzed in the parametric study. An agreement between these two results demonstrated the conformity of this numerical model.

\section{Numerical procedure}

\subsection{Experimental data}

In this numerical study, the experimental results in ref (Rambo and et al., 2015; 2016; 2017) on the mechanical behavior of basalt TRC at room temperature were used as input data. In these 
experimental researches, the tests in direct traction on the specimens of the basalt textile reinforced cement matrix were conducted for the characterization of tensile mechanical behavior (see Figure 1). In order to find the effect of the reinforcement ratio on this behavior, the layer number of basalt textiles was raised from one to 5 layers, corresponding with the cross-section reinforcement ratio from $0.40 \%$ to $1.99 \%$.

As the results obtained, the basalt TRC specimens presented the strain-hardening behavior with two or three phases, as in the literature (see Figure 1). The stage I corresponds to the elastic-linear range where both matrix and basalt textile behave linearly. Stage II is the phase of cracking where it could be found the drop-in stress on the stress-strain curve. The thirst one is nearly linear, and after that is the failure of TRC specimens in an abrupt way. Concerning the effect of the layer number on the ultimate strength of basalt TRC specimen, it was found that the use of 3 and 5 layers of basalt textiles gave great improvements. In comparison to the ultimate strength of the unreinforced matrix, this value increases from 1.2 to 2.6 times corresponding with the two cases of basalt textile reinforcement.

Concerning the experimental result on the constituent materials, the ultimate strength obtained was $688 \mathrm{MPa}$ for the basalt textile sample, while the value of Young's modulus was $62.5 \mathrm{GPa}$. The concrete matrix gave a capacity of 3.5 MPa in tension and Young's modulus of $34 \mathrm{GPa}$ (Rambo and et al., 2015; 2016; 2017). All results on the constituent materials were used as input data in the numerical model.

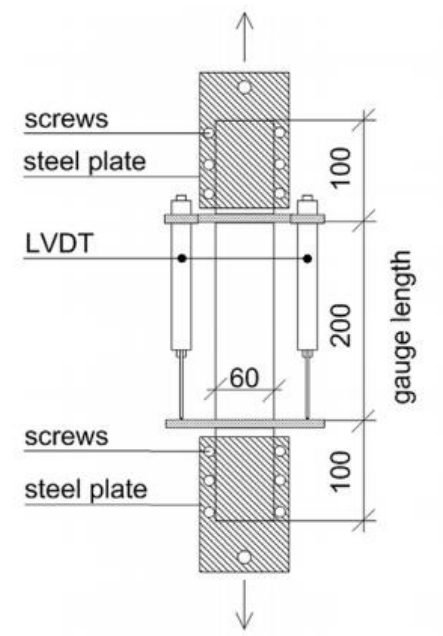

\subsection{Numerical model}

A 2-D model of basalt TRC specimen was built by using the finite element method in the ANSYS software. This model had the same geometry, configuration, and dimensions as the specimens in ref (Rambo and et al., 2015; 2016; 2017). It aims to simulate the mechanical behavior of basalt TRC under direct traction force. In the experiment, the dimension of basalt TRC specimens was $400 \mathrm{~mm} \times 60 \mathrm{~mm} \times 13 \mathrm{~mm}$ (length $\mathrm{x}$ width $\mathrm{x}$ thickness). Due to the symmetry of loading, boundary conditions, and materials, a model of a half specimen was constructed by using the finite element codes in the ANSYS Mechanical. That reduced the total number of elements for saving calculation time.

\subsubsection{Element types}

The element types chosen for the mechanical analysis in the 2-D model were the PLAN183 element (2D 8-Node Structural Solid) for the cement matrix and basalt textile, and the cohesive element INTER203 (2-D 6- Node Cohesive) for the interface between fiber and matrix (see Figure 2).

\subsubsection{Material model}

In this numerical modeling, the BISO (Bilinear Isotropic Hardening Specifications) model was used to simulate the work of the cement matrix or concrete under the loading action. However, for an agreement with the mechanical behavior of the cement matrix, a reduction coefficient was used after reaching the stress $\sigma_{0}$ on the stress-strain relationship

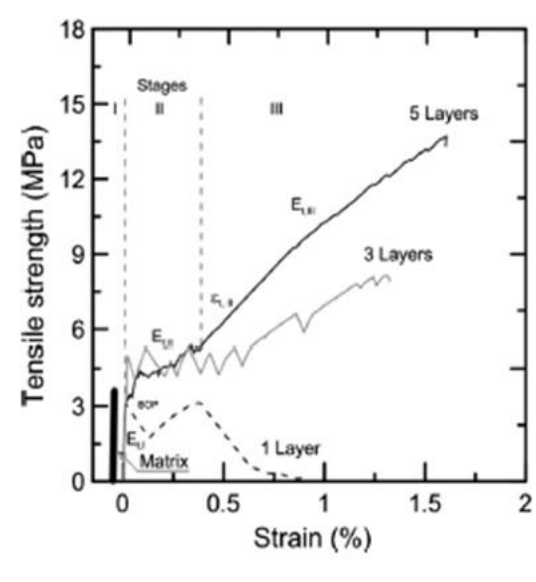

Figure 1. Experimental works on the basalt TRC composites in Rambo's works. 
(see Figure 3). It means that the concrete matrix gives bilinear behavior, and there is a negative trend in the second phase. The reduction coefficient depends on the reinforcement ratio because the presence of basalt textiles as the reinforcement changed the response of the cement matrix slightly. The material model chosen for the basalt textile was the perfect elastic. That means the basalt textile provides a linear behavior until its failure. The ultimate strength and Young's modulus are important parameters for this material model. This simulation is reasonable for the basalt textile, and it also has been used in the literature (Rambo et al., 2017; Blom and Wastiels, 2013).

For the interface between the basalt textile and cement matrix, the cohesive bilinear zone material model (CZM) was used. This material model was proposed firstly by Alfano and Crisfield in their work (Alfano and Crisfield, 2001). It was then used and developed in the ANSYS software for the interface model between two materials. In this case, the interface elementprovides bilinear behavior, and this model assumes that the separation of the material interfaces is dominated by the displacement jump

tangent to the interface, as shown in Figure 4. The relation between tangential cohesive traction $T_{t}$ and tangential displacement jump $\delta_{t}$ can be expressed as:

$$
T_{t}=K_{t} \delta_{t}\left(1-D_{t}\right)
$$

Where: $K_{t}$ : tangential cohesive stiffness; $\tau_{\max }$ : maximum tangential cohesive traction ; $\delta_{t}^{*}$ tangential displacement jump at maximum tangential cohesive traction; $\delta_{t c}$ tangential displacement jump at the completion of debonding; $D_{t}$ : damage parameter associated with mode dominated cohesive bilinear law, defined as:

$D_{t}=\left\{\begin{array}{cc}0 & \delta_{t}^{\max } \leq \delta_{t}^{*} \\ \left(\frac{\delta_{t}^{\max }-\delta_{t}^{*}}{\delta_{t}^{\max }}\right)\left(\frac{\delta_{t}^{c}}{\delta_{t}^{c}-\delta_{t}^{*}}\right) & \delta_{t}^{*} \leq \delta_{t}^{\max } \leq \delta_{t}^{c} \\ 1 & \delta_{t}^{\max }>\delta_{t}^{*}\end{array}\right.$

Where: $T_{t}$ max: Maximum tangential cohesive traction; $\delta_{t}^{*}$ : Tangential displacement jump at maximum tangential cohesive traction; $\delta_{t}^{c}$ : Tangential displacement jump at the completion of debonding.
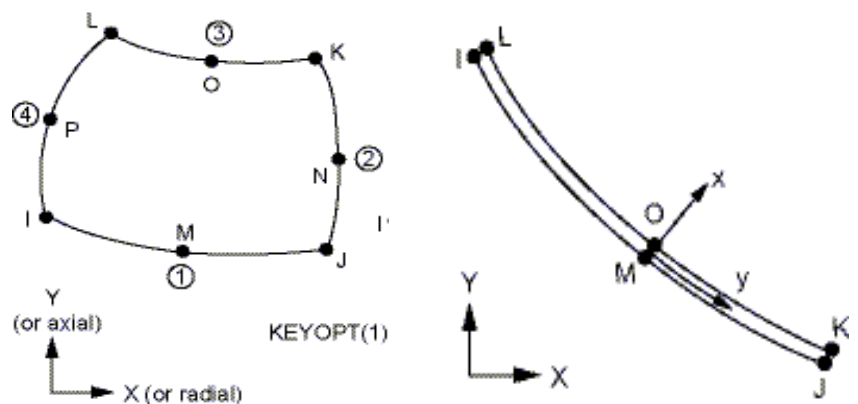

Figure 2. Element types used in the 2-D model. (a) PLAN183 element; (b) INTER203 element.

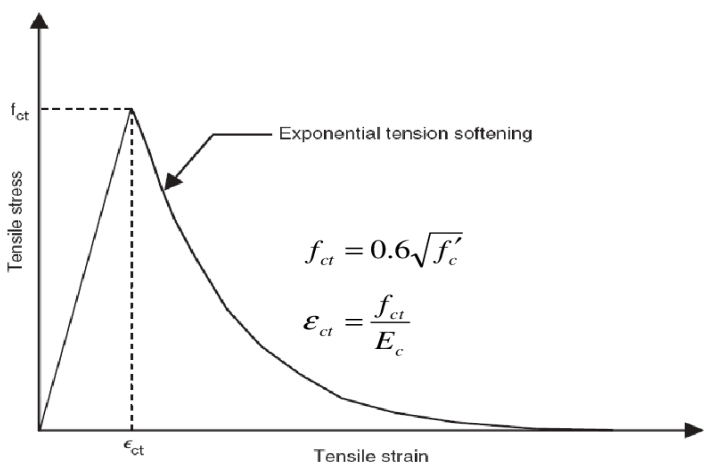

Figure 3. Model of the material for the cement matrix (BISO with a reduction coefficient).

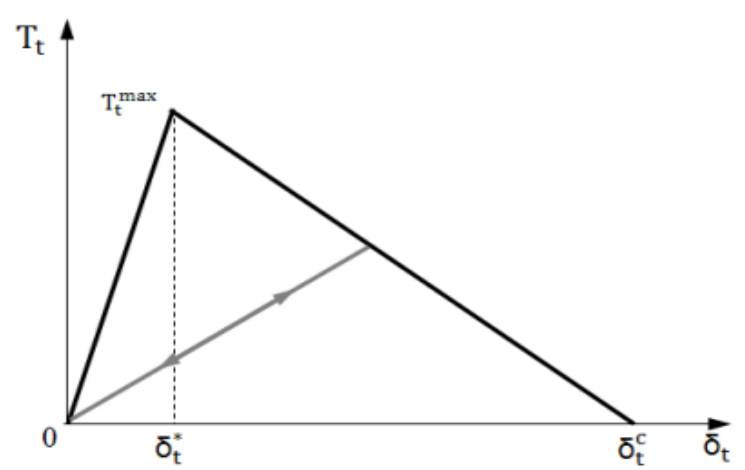

Figure 4. Cohesive bilinear zone material model for the interface. 


\subsubsection{Material properties}

The experimental results in ref (Rambo et al., 2015 ; 2016; 2017) were chosen as input data in the numerical model. These data had been used in the different finite analysis proposed by Rambo et al. (2017) in their research. However, to correspond with the finite element model in this numerical study, Young's modulus of the basalt textile and the concrete matrix need modifying. The calculated parameters of numerical modeling as Young's modulus and tensile strength of basalt textile and cement matrix were presented in the following Table 1.

\subsubsection{Mesh, boundary conditions and loads}

The 2-D numerical model was created by using the codes in ANSYS MECHANICAL. In this model, the reinforcement of basalt textile was made by a layer with the thickness depending on the reinforcement ratio (see Figure 5). This value was calculated from the cross-section of basalt textile and TRC composite. In order to find the effect of the reinforcement ratio on TRC's behavior and ultimate strength, a parametric study was carried out by changing its value from $0.4 \%$ to $2.5 \%$, corresponding respectively to the reinforcement ratio of one and 5 basalt textile layers. The thickness of the basalt textile layer in the 2-D model was from $0.02583 \mathrm{~mm}$ to $0.1625 \mathrm{~mm}$.

Concerning the meshing of the elements in the numerical model, the type of rectangular mesh with different sizes was chosen. The basalt textile layer in the TRC composite is divided equally by five over its thickness. The cement matrix layer was also divided by ten over its thickness, but the mesh with different sizes for the transmission between the fiber and matrix element sizes (see Figure. 5). As regarding the boundary conditions of this model, the displacement $D_{X}=0$ was imposed with all the nodes at the left end of the sample, and then, $D_{Y}=0$ with all the nodes at the sample axis. The boundary conditions of the sample were conducted in symmetry way, as shown in the following Figure 5.

The tensile load was imposed by the imposed displacement of all nodes at the right end of the sample. In order to characterize more precisely the TRC's behavior at the first phase (because of a very small strain of the sample), there were two loading steps in the numerical program. The rate of the imposed displacement was modified by the time for each loading step and sub-steps. In this numerical study, the number of sub-steps was 50 for each loading step.

Table 1. Calculated parameters used in the numerical model.

\begin{tabular}{|c|c|c|c|c|}
\hline \multicolumn{2}{|c|}{ Basalt textile } & \multicolumn{2}{c|}{ Cementitious matrix } & Fiber / Matrix Interface \\
\hline $\begin{array}{c}\text { Young's modulus } \\
(\mathrm{GPa})\end{array}$ & $\begin{array}{c}\text { Tensile strength } \\
(\mathrm{MPa})\end{array}$ & $\begin{array}{c}\text { Young's modulus } \\
(\mathrm{GPa})\end{array}$ & $\begin{array}{c}\text { Tensile strength } \\
(\mathrm{MPa})\end{array}$ & $T_{\max }(\mathrm{MPa})$ \\
\hline 43.2 & 688 & 34 & 3.5 & 2.9 \\
\hline
\end{tabular}

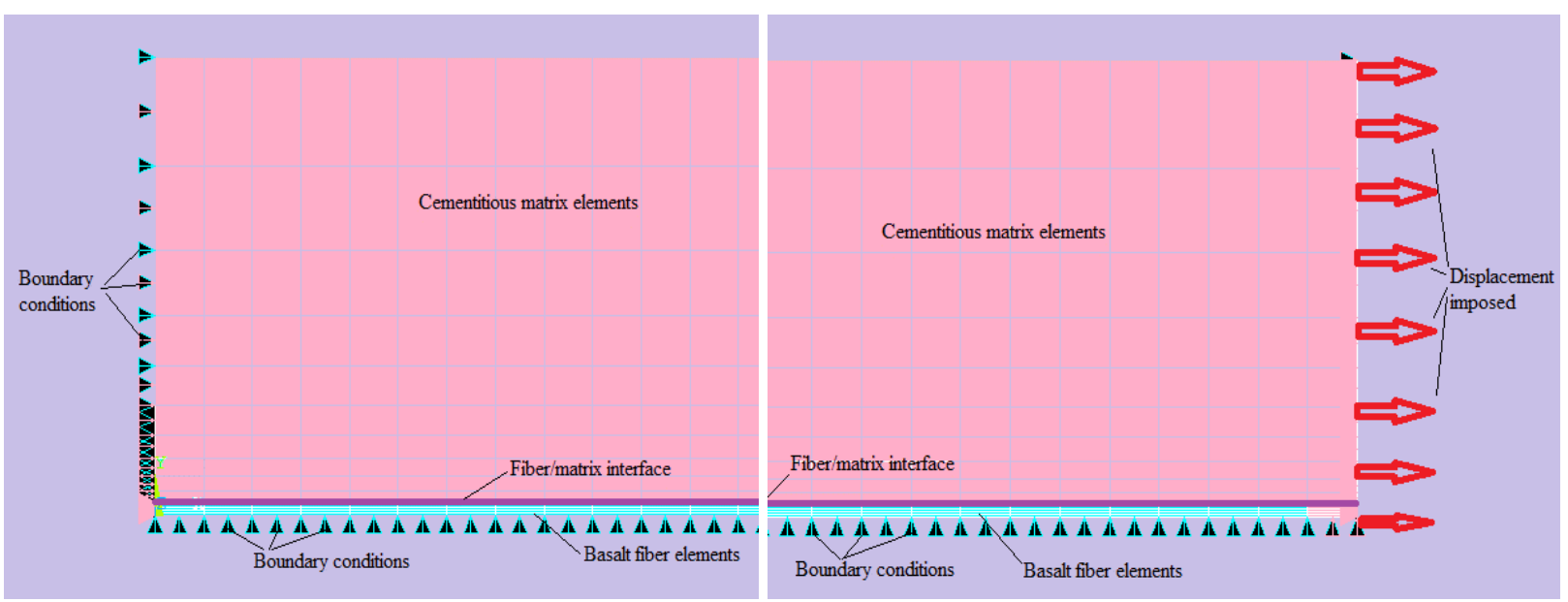

Figure 5. Configuration of the matrix, fiber and interface elements in the 2-D model. (a) At the left end; (b) At the right end. 


\section{Numerical results}

\subsection{Mechanical behavior of basalt TRC composite}

The numerical results obtained from the 2-D finite element model corresponding to the Rambo's data were interesting. The numerical model presents the distribution of stress and displacement at all nodes of the specimen at each step of numerical calculation (see Figure 6). Therefore, it could be exploited the global behavior of basalt TRC from all nodes at the same cross-section. As numerical results, the numerical model gave differently "stress-strain" curves depending on the reinforcement ratios. In Figure 7, it could be found that the ultimate strength of basalt TRC increased with the raising of the reinforcement ratio from $0.4 \%$ to $2.5 \%$.

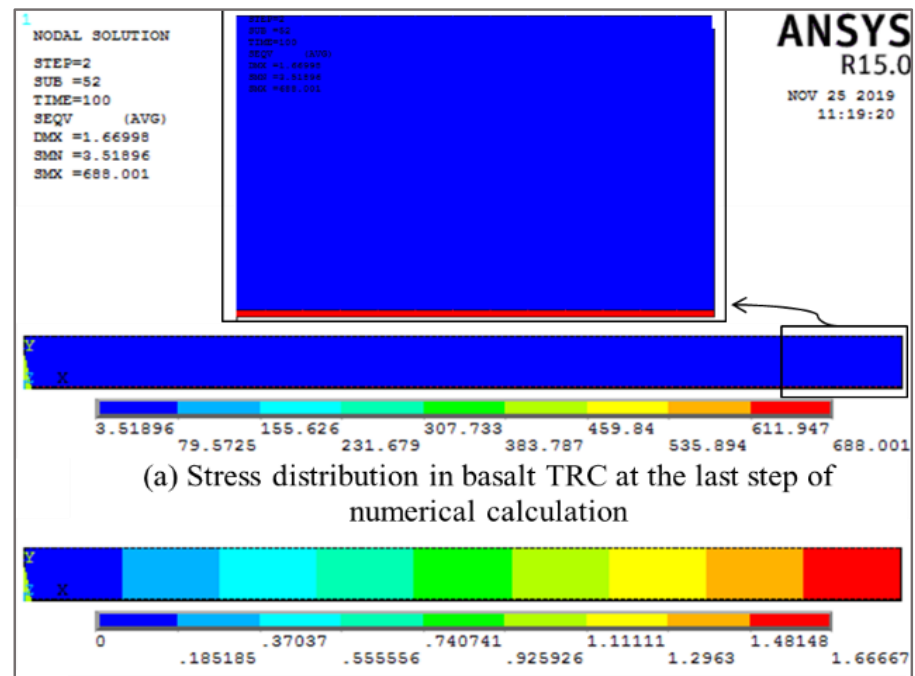

(b) Distribution of displacement of all nodes on the specimen

Figure 6. Distribution of stress and displacement on the specimen at the last step of numerical calculation.

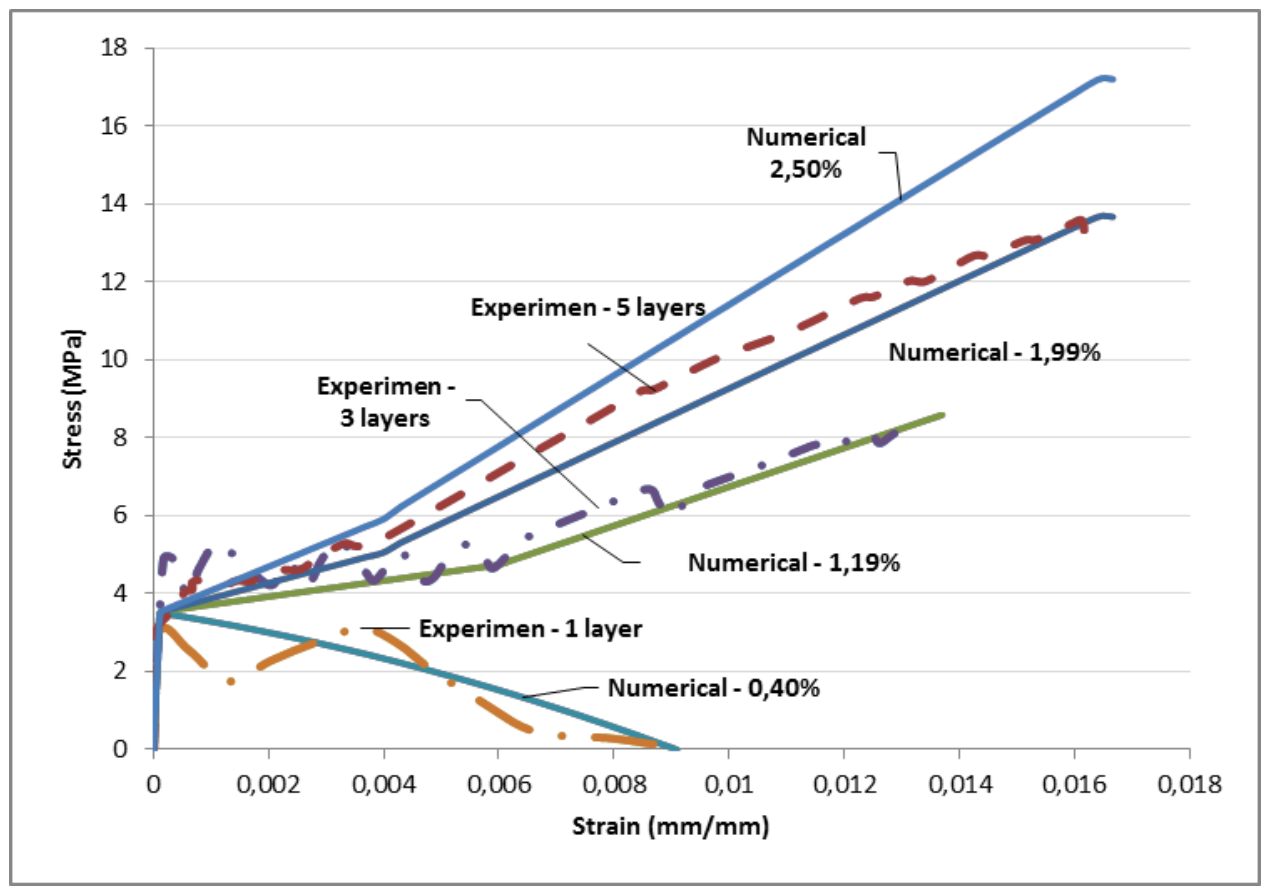

Figure 7. Comparison of numerical and experimental results. 
The TRC composite model with the reinforcement ratio of $0.4 \%$ gave a "stress-strain" relationship with two phases.

The first phase was almost linear to the cracking point, and in the second phase, the stress reduced to the negligible value with the increasing of the strain. With the bigger reinforcement more $(1.19 \%, 1.99 \%$, and $2.50 \%)$, the basalt TRC gave a strain-hardening behavior with three distinguishable phases. The typical values of the "stress-strain" relationships are presented in Table 2.

According to the experimental studies, the definition of the mechanical properties of the basalt TRC composite was made for the numerical results. The first phase was characterized by the crack stress $\left(\sigma_{B O P}\right)$, the initial rigidity $\left(E_{t, I}\right)$ and the strain at the point I $\left(\varepsilon_{B O P, I}\right)$. The second phase was also characterized by the stress $\left(\sigma_{t, I I}\right)$ and strain $\left(\varepsilon_{t, I I}\right)$ at point II where the TRC specimen has been cracked completely and this was the beginning of the thirst phase.

The stiffness of this cracking phase was defined as the average slope of the second phase of the "stress-strain" curve $\left(E_{t, I I}\right)$. The point corresponding to the rupture of the TRC specimen was called UTS (ultimate stress) point. The ultimate strength $\left(\sigma_{t, U T S}\right)$ and ultimate strain $\left(\varepsilon_{t, U T S}\right)$ were the corresponding values at this point, while the post-cracked rigidity $E_{t, I I I}$ was defined as the average slope of the thirst phase of the "stress-strain" curve.

In comparison with Rambo's experiment data, it could be found an interesting agreement between both results. The cracking stress was 3.55 and 3.54 MPa for the numerical model respectively of 3 and 5 basalt textile layers while this value was 4.09 and $3.45 \mathrm{MPa}$ in the corresponding experiment. The ultimate strength values were 13.67 MPa and 13.49 MPa for both numerical and experimental results in the case of 5 reinforcement layers and $8.59 \mathrm{MPa}$ and 8.44 MPa for another case.

\subsection{Effect of reinforcement ratio on the mechanical behavior}

From Figure 7, it could be found the change of the mechanical behavior of basalt TRC composite from strain-softening with two phases to strain- hardening with three phases when the reinforcement ratio was greater than a critical value (around in the range from $0.4 \%$ to $1.19 \%$ ). This value was a parameter to ensure the efficiency of the textile reinforcement. This critical value of the reinforcement ratio was calculated from equation 3 (Contamine 2011):

$$
V_{c r i}=\frac{\sigma_{M}}{\sigma_{f}}
$$

Where: $V_{\text {cri: }}$ critical value of the reinforcement ratio; $\sigma_{M}$ and $\sigma_{f}$ : maximum strength of the cement matrix and basalt textile.

From the experimental data, the critical reinforcement ratio calculated for this case was $0.51 \%$ in the range from $0.4 \div 1.19 \%$. This result is reasonable with the previous comments in this section. So, it could be said that the reinforcement ratio influenced the shape of stress-strain curves of basalt TRC's behavior. Furthermore, it could be found in Figure 7 that Young's modulus in the third phase of the stress-strain relationship increased with the raising of the reinforcement ratio while the length of the second phase was shortened.

\subsection{Effect of reinforcement ratio on the ultimate strength}

As the results presented in Table 3 , the ultimate strength of basalt TRC increased from $3.50 \mathrm{MPa}$ to $17.20 \mathrm{MPa}$ with the raising of the reinforcement ratio from $0.4 \%$ to $2.5 \%$. This result could be understood because of the assurance in strength from basalt textiles by its high performance.

However, the rising tendency is not linear. If the reinforcement ratio is less than the critical value (calculated from equation 3), the TRC's performance would be depended on that of the cement matrix. The ultimate strength of basalt $\mathrm{TRC}$, in this case, was around $3.50 \mathrm{MPa}$ with a higher value of the reinforcement ratio. The evolution of the ultimate strength as a function of the reinforcement ratio was linear (see Figure 8) in a comparison between the experimental data and numerical result. There was an interesting agreement that demonstrated the rationality of the 2-D numerical model. 
Table 2. Comparison of the numerical results obtained and Rambo's experiment.

\begin{tabular}{|c|c|c|c|c|c|c|c|c|c|c|}
\hline \multirow[b]{2}{*}{ Results } & \multicolumn{4}{|c|}{ First crack values } & \multicolumn{6}{|c|}{ Post crack values } \\
\hline & $\begin{array}{l}P_{B O P} \\
(\mathrm{kN})\end{array}$ & $\begin{array}{c}\sigma_{B O P} \\
(\mathrm{MPa})\end{array}$ & $\begin{array}{l}\varepsilon_{B O P, I} \\
(\%)\end{array}$ & $\begin{array}{c}E_{t, I} \\
(\mathrm{GPa})\end{array}$ & $\begin{array}{l}P_{U T S} \\
(\mathrm{kN})\end{array}$ & $\begin{array}{c}\sigma_{U T S} \\
(\mathrm{MPa})\end{array}$ & $\begin{array}{c}E_{t, I I} \\
(\mathrm{GPa})\end{array}$ & $\begin{array}{c}E_{t, I I I} \\
(\mathrm{GPa})\end{array}$ & $\begin{array}{l}\varepsilon_{t, I I} \\
(\%)\end{array}$ & $\begin{array}{c}\varepsilon_{U T S, I I I} \\
(\%)\end{array}$ \\
\hline $\begin{array}{l}\text { Numerical of } 1 \text { layer } \\
(0.4 \%) \text {. }\end{array}$ & - & 3.50 & 0.012 & 33.23 & - & - & - & - & - & - \\
\hline Experiment of 1 layer. & 2.59 & 3.58 & 0.016 & 28.29 & - & - & - & - & - & - \\
\hline $\begin{array}{l}\text { Numerical of } 3 \text { layers } \\
(1.19 \%) \text {. }\end{array}$ & - & 3.55 & 0.019 & 33.32 & - & 8.59 & 0.207 & 0.50 & 0.58 & 1.370 \\
\hline Experiment of 3 layers. & 3.29 & 4.09 & 0.019 & 24.65 & 6.79 & 8.44 & 0.096 & 0.43 & 0.70 & 1.360 \\
\hline $\begin{array}{l}\text { Numerical of } 5 \text { layers } \\
(1.99 \%) .\end{array}$ & - & 3.54 & 0.013 & 33.9 & - & 13.67 & 0.395 & 0.692 & 0.40 & 1.649 \\
\hline Experiment of 5 layers. & 2.85 & 3.45 & 0.011 & 34.64 & 11.13 & 13.49 & 0.450 & 0.67 & 0.42 & 1.580 \\
\hline
\end{tabular}

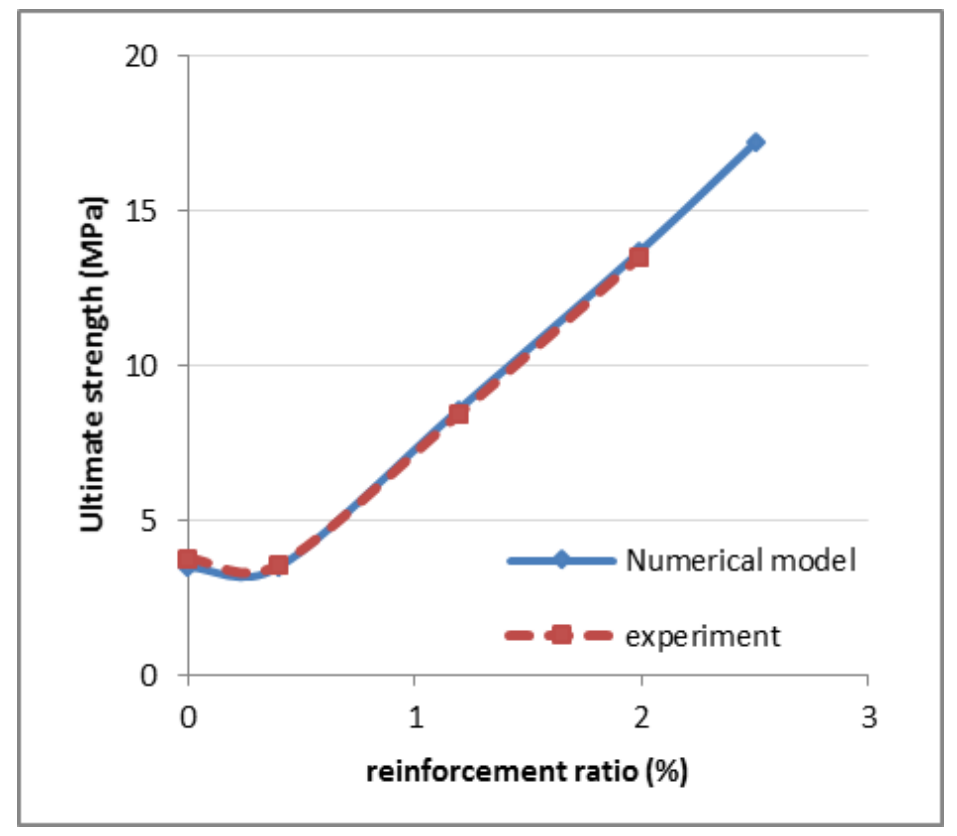

Figure 8. Evolution of the ultimate strength as a function of reinforcement ratio.

\section{Conclusions.}

A 2-D finite element model was developed to characterize the mechanical behavior of the basalt textile reinforced concrete (TRC) composite at mesoscale. This model was validated and verified with the data from experimental tests performed by Rambo et al. The following conclusions can be drawn from the numerical results and experimental research:

The model agrees reasonably with experimental results. Consequently, the model could be used to predict the TRC's behavior from that of the constituent materials. The mechanical properties of TRC composite such as cracking stress, ultimate strength, strain at typical points, and Young's modulus of the three phases, also could be predicted.

A parametric study shows the great effect of the reinforcement ratio on the stress-strain relationship and the ultimate strength of the basalt TRC. A positive trend of ultimate strength as a function of the reinforcement ratio was found. In comparison with the experimental data, the numerical model gave reasonable results.

This numerical model could not present the failure mode of basalt TRC specimens. For future work, it will be interesting to build a 3-D 
numerical model in which the cracking of the cement matrix could be taken into account. With that model, the failure mode of TRC specimens by multi-cracks could be observed after the numerical test.

\section{References}

Alfano. G., and Crisfield. M., (2001). Finite element interface models for the delamination analysis of laminated composites: mechanical and computational issues. International journal for numerical methods in engineering 50(7). 17011736.

Blom. J. and Wastiels. J., (2013). Modeling textile reinforced cementitious composites - effect of elevated temperatures. The 19th international conference on composite marerials.

Brameshuber. W., (2006). Textile Reinforced Concrete - State-of-the-Art. Report of RILEM TC 201-TRC. 292.

Butler. M., Lieboldt. M., Mechtcherine. V. (2010). Application of textile-reinforced concrete (TRC) for structural strengthening and in prefabrication. in: G. van Zijl. W.P. Boshoff (Eds.). Advances in Cement-Based Materials. Taylor \& Francis Group. London 127-136.

Colombo. I., Colombo. M., Magri. A., Zani. G., di Prisco. M., (2011). Textile Reinforced Mortar at High Temperatures". Applied Mechanics and Materials. 82. 202-207.

Contamine. R., (2011). Contribution à l'étude du comportement mécanique de composites textile-mortier application à la réparation et/ou renforcement de poutres en béton armé vis-à-vis de l'effort tranchant. Université Claude Bernard (Lyon). E. École Doctorale Mécanique Génie Civil. Acoustique (MEGA). and LGCIE - Laboratoire de Génie Civil et d'Ingénierie Environnementale.

Djamai. Z., Bahrar. M., Salvatore. F. Si Larbi. A., El Mankibi. M., (2017). Textile reinforced concrete multiscale mechanical modelling:
Application to TRC sandwich panels. Finite Element \& Analysis Design 135. 22-35.

Hegger. J. and Voss S., (2008). Investigations on the bearing behaviour and application potential of textile reinforced concrete. Engineering Structures 30(7). 2050-2056.

Hegger. J., Will. N., Bruckermann. O., Voss. S., (2006). Load bearing behaviour and simulation of textile reinforced concrete. Materials and Structures 39(8). 765-776.

Mechtcherine. V., (2013). Novel cement-based composites for the strengthening and repair of concrete structures. Review article. Construction \& Building Materials 41. 365-373.

Mobasher. B., Peled. A., Pahilajani. J., (2006). Distributed cracking and stiffness degradation in fabric-cement composites. Material and Structure 39(3). 317-331.

Rambo. D., de Andrade Silva. F., Toledo Filho. D., Gomes O., (2015). Effect of elevated temperatures on the mechanical behaviour of basalt textile reinforced refractory concrete. Material \& Design. 65. 24-33.

Rambo. D,. Silva. F., Toledo Filho. R.. Ukrainczyk. N., Koenders. E., (2016). Tensile strength of a calcium-aluminate cementitious composite reinforced with basalt textile in a hightemperature environment. Cement Concrete Composite 70. 183-193.

Rambo. D., Toledo Filho. R., Mobasher. B., (2017). Experimental investigation and modelling of the temperature effects on the tensile behaviour of textile reinforced refractory concretes. Cement and Concrete Composites 75. 51-61.

Truong. B. T., (2016). Formulation. performances mécaniques. et applications. d'un matériau TRC pour le renforcement et la réparation de structures en béton/et béton armé : Approches expérimentale et numérique. phdthesis. Université de Lyon. 